\title{
4 \\ Are we there yet? Government online: Lessons from New Zealand
}

\section{Colin MacDonald}

In terms of governance, the New Zealand environment is quite different, of course, to Australia's: we have the pleasure of only having two layers of government-central and local. We have just over 30 central government departments, and 78 local government authorities. New Zealand has 4 million people_-and a widespread diaspora of 1 million overseas. One of the things that is really important to our current government, and therefore to all of the public service, is the delivery of better public services. This is one of the government's four priorities, along with responsibly managing finances, building a more productive and competitive economy and supporting the Christchurch rebuild after the 2011 earthquake.

We at the Department of Internal Affairs New Zealand have the responsibility of leading one of the results embedded in the delivery of better public services, which is Result $10,{ }^{1}$ aimed at making it easy for citizens to transact in a digital environment. But, interestingly, the department is also the home of a role called the government chief digital officer, occupied by me. It's one of three functional leadership roles in

1 Since 2012, a group of 10 agencies, in an initiative known as 'Result 10', have been given a mandate to radically change the way government delivers services. Working collaboratively to develop joined-up, integrated life-event products and services across government, enabled through digital and secure options, the aim is that by 2021,80 per cent of the most common transactions with government will be completed digitally. 
our government and entails my trying to work across silos: interesting and challenging for anyone who's tried to do that because all of our accountability models go up to ministers and yet services to citizens go across the silos. This is one of the key themes of this volume: citizen-centricity.

I think it's a huge opportunity. Because, for me, when I think about the problem, the challenge, the opportunity of digitising government, sometimes I can become quite daunted. There's a lot to be done. There's a lot of ways we can change and do things differently. I think the prize is absolutely enormous. And as public service leaders, we have a phenomenal opportunity to make a real shift in the way citizens experience government. (By 'public sector leaders', I don't simply mean 'public administrators'-if we think of ourselves solely as administrators we might as well all go home because digitising government needs real leadership. It is administrative leadership rather than political leadership but it needs leadership nonetheless.)

My contention is that the traditional government service models are no longer fit for purpose. They do not even come close to meeting what citizens are experiencing in other parts of their lives; we are a long way from 'Amazon-like' government. ${ }^{2}$ If it was truly an Amazon-like government experience, it would be completely different to what it is today. It would be much easier for the customer. We would be connecting the dots behind the scenes. We would not be waiting until somebody applied-for example, we would be proactively offering people the opportunity to get their entitlements.

It would be faster. It would be more efficient and we would be doing quite a different job. But how? To be frank, I'm not quite sure. That may be a terrible admission coming from the chief executive of a government department, but I don't know how to achieve this, other than having a clear vision and taking it one step at a time. Importantly, we actually have to get started doing things. We are working in what is effectively an organic system. It is too complex to be knowable. Intervention logic does not work here.

2 Amazon doesn't ask customers to deal with its packing website and then its shipment site, but governments still ask citizens to navigate their internal bureaucracy. In an Amazon-like government, this bureaucracy still exists, but is behind the scenes of the citizen experience. 
We have to try things, we have to disrupt the status quo and we have to see what happens. We have to then respond to that change to the system. It is quite a different thing and it is quite hard, I think, for us to do an Amazon level of experimentation, given the pressure on us from politicians and the public. Instead, I think we need some golden rules.

First, put the customer at the centre. This is of course easy to say and incredibly difficult to do because citizens are individuals: they have unique needs, expectations and contexts that we won't always know. There are broadly two types of customers we need to think about: those to whom we deliver services; and those we regulate. Because, after all, we are still regulators. The time may come when we truly have an Uber experience where we are all regulating each other; but, until that happens, government still has a role to set the rules and to try and help society work in a sensible way.

To this end, in New Zealand we have put a lot of effort into trying to understand customer needs, divided into stages. Stage one has been about identifying some customer personas, to act as ways of helping people to think about the different types of customers they might be dealing with. Much work has gone into trying to say that, broadly speaking, there are these types of citizens who have these types of characteristics.

But while this gets us started on the journey, it is still only a proxy for actual customer experience. And yet, when I think about where we are and where we are trying to get to, it's not a bad start. For example, in New Zealand we have over 500 government websites. We stopped counting once we reached 500. And that's just for our central government. All of the sites have a different look and feel, they have different approaches, but most of them cannot actually complete your transactions online. To take this next step forward, we have produced a new website, www.govt.nz.

We were inspired and helped by colleagues in the UK. They gave us all of their source codes and we went through an alpha and a beta test and we launched the website. But within six weeks, despite all this hard work, we had changed it dramatically. This isn't to say I am critical of the process. We did exactly the right thing, particularly at the point when the team came back to me and said they wanted to make a significant change to the look and feel of the site, even though it had only been running for six 
weeks. It was exactly the right thing to do because, while the initial site was nice and easy for people to use and to find information, it didn't feel authoritative; it didn't feel like government.

Consequently, we tweaked it. We changed the typeface, we changed the colours to make it look a little sterner. We learnt this lesson: in our effort to become user-centric, we created such a different experience for users that they didn't trust it to the level that we wanted them to.

Part of putting government at the centre in the digital world is to make sure we can really easily figure out that the person at the other end of the bitstream is who they say they are. In New Zealand, to do this, we have a product called Real Me. It started off as a purely government product, but we have now partnered with New Zealand Post, a state-owned enterprise, to deliver it into the private sector as a product that they might want to use in their digital world. The reason we've done that is because we realise that people transact infrequently with government. And there are three things that this authentication product can do.

The first thing it can do is let you log on to a service. The second thing allows you to verify your identity. But, importantly, the third thing it enables is allowing you to exchange information in a way that you can control and manage. To borrow an example given by Tamati Shepherd elsewhere in this volume (Chapter 13), in the future when you change your address online, all of the agencies to whom you've given permission will be able to receive that address change. If you don't have the identity piece solved, in my view, getting the digital piece solved will simply not happen. And I know in the UK they have taken a different approach to this, using the private sector to figure out the authentication problem. I'm not convinced that this is something that we can leave to the private sector. While there is much the private sector can do, I'm not sure that deferring to them the level of authority to confirm that somebody is who they say they are is what we in government want. Time will tell if that's a wise decision.

My second golden rule is to design services around life events. People don't get up in the morning and think, 'I'd really like to get in touch with the Department of Internal Affairs today, they're nice folks, we'll have a nice chat'. They tend to give us a ring when they want to go overseas, 
for example, they want to get their passport. It's not so much that they want to get their passport; they want to travel. So we've put a lot of energy into making it really easy to get your passport.

New Zealand is the only country in the world where you can apply for and have your passport approved online. It is then posted to you, typically in three or four days. It is a world-leading service. We are not going to put much more money into it because it's a standalone service. The next step to improve it will be to find ways of integrating it into people's livesperhaps on the Air New Zealand website. When you try to book your flight, for example, should you not have a valid travel document, you could apply via the airline website. Because that would be a much more sensible way of doing it.

We are currently identifying a whole range of life events with which we can integrate our services. The first one is the birth of a child event. When your child is born, instead of having to then go and register with multiple departments, ideally, you would be able to do this via an app. New parents are busy. Using such an app would be much easier than having to go to wherever the relevant government office may be when you've just had a baby.

This is an example of why figuring out design around life events is crucial. It is also hugely challenging, because we can't simply stay within our own organisational silos. In fact, I believe this is the most fundamental challenge to our current operating model in terms of government. This will be a very big issue to solve and, if we don't do it, it will eventually trip us up.

To avoid this scenario, we have to work differently. We can no longer work as a simple service provider or a government department. We have to work within a system of services. This is the third golden rule. To this end, in New Zealand, we are trying to take a hybrid approach. We describe it as being centrally led but collaboratively delivered. There is no way that I can see somebody at the centre orchestrating all of this. And yet, somebody does have to take a leadership role and try and help others by guiding the way. That is effectively my role, to try and provide that overall guidance while chief executives remain accountable for delivery within their own organisations. 
Fortunately, the state services commissioner has now put an expectation on all chief executives that, along with me, they will take a leadership role. They must play fairly and join in: it's a question of trying to balance agency and system priorities.

Neither of my first three golden rules have anything to do with technology. The fourth one does. We will have to transform information and communications technology (ICT) to succeed. We have built our systems and our methods and our ICT shops individually and separately. What we need to do instead is start driving an ICT ecosystem that actually does work together. In New Zealand, a lot of energy over the last couple of years has also been put into the backend of all of this, the stuff that a few of us get very excited about.

I get excited about it. I have been playing in the computer science space for a long time. This topic interests me because I know how much payback you can get. And so we have done a lot of work trying to encourage agencies to take ICT as a service offering rather than continue to invest in their own infrastructure. Not just because it saves money, but because when we come to start looking at how we exchange information, how we create end-to-end business processes, if they're all being built on consistent platforms, those business processes will work together much better. The information flows will be much more straightforward.

It also gives us an opportunity to build stronger security across the ecosystem because, at the end of the day, all of this needs increased public trust and confidence. There is a fundamental difference, in my view, between trust in public and private institutions. If citizens lose trust in government, they don't have a choice-they cannot simply say 'to hell with that, I shall get my passport from somebody else'. They can try, but it would be a bad idea because in doing so they would be breaking the law.

Compare this to the private sector. If I have a bad experience with ANZwho I used to work for so I feel I can name them-I can simply take my business elsewhere. I have a choice. Citizens do not have a choice about who they can draw services from. Therefore, service quality and efficiency becomes one of the pillars that underpins trust and is part of the fundamental relationship between the citizen and the government. In turn, it is incredibly important that we maintain that trust. But we lose their trust if we don't transform the services to look more like the services 
that citizens experience in the rest of their lives. If we do this badly and we breach privacy, we will lose trust. If we don't do it, we will lose trust. Our only choice is to do it well and gain and maintain trust.

To reiterate, only one of the four golden rules is about technology. Most of the challenges are actually about how we tackle this problem. And, in my view, we are reinventing the way citizens interact with government, and there isn't the same level of risk tolerance as there is in the private sector, there is a different level. But I do actually echo the points that we have to try things but we also have to create an environment where we are trusted to try things. That requires an interesting conversation with ministers. How many of your ministers have said, 'go on out there and fail'? 'Go and get us on the front page of the newspaper for that service failure, that will be a good thing.'

We all know what that is like. We have all been there, one way or another. The wonderful thing about the private sector is you can bury your mistakes. You can actually refuse to give information about your failures. The private sector can do this. We as public servants cannot. Unfortunately, that means the risk is much greater for us, but in my opinion, if we don't make those aforementioned changes, we will lose citizen trust. Consequently, we must tackle some big rocks.

I think one of the big rocks is the service or operating model across government. As agencies, each of us is currently providing our own service; each of us thinking about the customer as a customer of our agency. We have to figure out a way to break that mindset, and instead start thinking about people as citizens of the government, customers of the government. We have to figure out how to manage these trade-offs between the system approach and the agency approach.

This isn't easy. When you've got a minister screaming in your ear saying they want benefit payment done on time and they don't care about whole of government, and you've got another minister in your other ear saying they want the experience of government to be changed, we are the ones caught in the middle. But it is our job to take leadership of that and find the way through. It is not a political issue. Politicians consider it to be public service business, so we simply have to get on with it.

For me, the big challenge in all of this is governance and accountability. What do public servants do when they are not sure what to do? You've heard it before: we set up committees. This is what we have done. We have 
set up one called the ICT Strategic Leadership Group. I'm not usually proud of committees, but I am of this one. Because in this case, I have managed to secure the time and the energy of 10 of my chief executive colleagues to sit on that ICT Strategic Leadership Group.

Here's the secret of its success. This isn't really about ICT. This is about transforming government. Consequently, of the groups that report to this and are guided by this committee, only one of them concerns technology. The other three are about much more interesting and important things like the service innovation, the service experience, the sharing and management of information, the mining of information, the use of information to drive better outcomes for citizens, and figuring out how the funding models and any revenue models have to change in order to support this approach. Because, as earlier stated, our old models won't support us.

We have managed to make progress but, I can tell you, some of the stuff that has been hardest has been getting our public management approach to fit a cross-horizontal, sectoral method. Within those groups, we have got more than 50 senior leaders. These are involved chief executives or second-tier leaders, from 19 central government agencies. The cynical amongst them might think it's just me trying to spread the blame if things go wrong, but I firmly believe it is time to spread leadership and get more people on this journey.

Earlier in this chapter, I mentioned funding as being one of the big challenges, and one of the learnings for me in this area is to follow the money. If you can figure out how to follow the money (or ideally, lead the money), this will get much easier. And one of the things I think we have to do next is look at how we approve investment in agency-based transformations. I know that Singapore is doing interesting work in this area, involving a balance between an agency investment and a system investment. I think we need to move that way as well.

But, in the end, it's all about the benefits. For me, this means trust and confidence. It all comes back to that. If we get that right then citizens will start to consider government to be an effective and an efficient partner. And it will start to talk to issues such as the lack of engagement between citizens and government (fewer people voting, fewer people getting involved). Technology is not the answer, but it is one of the tools we can deploy within this change in experience. 
To return to the question: are we there yet? In his contribution to this volume I think Tamati Shepherd was right when he mused that if we think we are then we are probably on the wrong journey. No, we're not there yet. We have taken some steps. We are making some progress. As an example, the Result 10 target is that, by 2021, 80 per cent of New Zealanders' most common transactions will be online. In 2015, the figure was 46 per cent. That continues to be a challenging target. As for Real Me, we have got $62 \log$-in services delivered through 20 agencies. We have more than 2 million accounts, driving millions of log-ins. We have 60,000 verified accounts, with that number growing rapidly.

Real Me is a quality product; it won the security and online safety award in the 2014 Australasian internet awards, and was a finalist in the UN public service awards in 2015.

Moreover, we are starting to deliver services around life events, although it is early days. There are two aspects to this: sharing for the customer, which is reusing their information and making it much easier for them to be able to do what they want to do; and sharing with the customer, in a privacy-protected way, providing information to service providers that those people may want to use.

Although I have not mentioned the private sector much in this chapter, my final point is that it has a huge role to play. Whether we talk about it as an Amazon-style system or something else, the idea of government as an ecosystem requires the creation of an environment whereby the private sector can come in and provide services that citizens can then choose to use.

And yet, we will have to set the rules. We will have to be what's called the ecosystem driver - if you talk to Amazon, that's what they did. Amazon drove that ecosystem. They decided where it was going to go, they decided what the rules were and they then attracted people towards them. As governments, not only do I think we can do that, I think we must do it. We need to drive the ecosystem. We need to make it not just okay for the private sector to play; we need to make it positively attractive because we cannot provide all the service needs that our citizens are going to be looking for in the future. 
This text is taken from Opening Government: Transparency and Engagement in the Information Age, edited by John Wanna and Sam Vincent, published 2018 by ANU Press, The Australian National University, Canberra, Australia.

doi.org/10.22459/OG.04.2018.04 